\title{
The Conceptual Design of Flexible Manufacturing System with the Use of Computer Simulation in Enterprise Dynamics
}

\author{
Piotr Barosz \\ Silesian University of Technology, Faculty of Mechanical Engineering, Gliwice, Poland \\ piotr.barosz@barosz.pl
}

\author{
Grzegorz Gołda , Ph.D \\ Silesian University of Technology, Faculty of Mechanical \\ Engineering, Gliwice, Poland \\ grzegorz.golda@polsl.pl
}

\author{
Adrian Kampa'Ph.D \\ Silesian University of Technology, Faculty of Mechanical \\ Engineering, Gliwice, Poland \\ adrian.kampa@polsl.pl
}

\begin{abstract}
Nowadays, production processes become more and more complicated because of global market competition and the need for flexible changes in production in order to meet the customer needs. That is related to frequent reorganization of production systems and require adequate operations management, internal and external logistic and project management from the stage of a conceptual design to the industrial implementation. Currently, we may observe an increased use of automation and robotization, which replace human labor. Modern industrial robots can work similarly to a human operator, but the replacement of a human operator with robot is related with some technical problems and excessive cost, therefore robotic workstations must be properly designed. The aim of the study is developing a method which allows estimation of productivity growth associated with the replacement of human labor with industrial robots at an early design stage. The production flow in the manufacturing system and internal logistic processes were modeled in the Enterprise Dynamics software, which enables simulation and visualization of discrete production processes. The models were built taking into account availability, performance and quality parameters, which enable a direct calculation of OEE (Overall Equipment Effectiveness) indicator, which is one of most important Key Performance Indicator (KPI) used in World Class Manufacturing (WCM) methodology, especially in automotive industry. The use of OEE indicator enables comparison with similar manufacturing systems. The example of conceptual design of the flexible manufacturing cell, with CNC machine tools, which can be operated by humans or robots, is presented. The production process includes two machining operations of large and heavy parts, which are difficult to handle, therefore robots are preferred to apply.

The computer simulation of the sophisticated model of flexible manufacturing system with machines, operators and robots with reliability parameters allows better representation and understanding of a real production process at the stage of conceptual design. The experiment results confirm the advantage of application of robotic operated production systems comparing to manually operated machines with production growth about $17 \%$.

However, robotization is related to very high investment cost, therefore detailed economic analysis is required, including comparison of labor cost and robot cost. Obtained results can be used for detailed designing of manufacturing systems and
\end{abstract} robotic workstations.

Keywords: management, automation, production, OEE - Overall Equipment Effectiveness, WCM - World Class Manufacturing

\section{Introduction}

Nowadays, we can observe an increasing global market competition that requires very flexible changes in production in order to meet the customers' needs. The production of more advanced products is related with the use of complex manufacturing systems, and therefore production processes are more and more complicated and difficult to analyze. That is related with frequent reorganization of production systems and requires adequate operations management, internal and external logistic and project management from the stage of a conceptual design to the industrial implementation. Designing complex Manufacturing Systems and Flexible Manufacturing Systems (FMS) requires taking different aspects into consideration (Doumeingts, Vallespir, \& Darracar, 1987), including manufacturing strategies, logistic system architecture, performance planning and evaluation, operation management techniques, risk assessment and scenario analysis. According to (Robinson, 2009), the first step of the designing process is

The current issue and full text archive of this journal is available at www.jraspublications.org/index.php/JRAS/issue/archive

Journal of Research in Administrative Sciences (JRAS)

VII(II), 1-6, ISSN: 2664-2433
Conceptual Design, which includes going from a description of the goal, through the requirements of the model, to a definition of what is going to be modeled and how.

The design process of FMS has to comply to a set of constraints defining the manufacturing processes, the product requirements, and used resources (including human resources). There are some methods and techniques for designing FMS described by (Tolio, 2009).

The formalism of FMS can be described (Kamble \& Hebbal, 2010) using the IDEF (Integration DEFinition) family of modeling languages, which is built on the basis of functional modeling language Structured Analysis and Design Technique (SADT). There are also other formalisms used including CIMOSA (CIM Open Systems Architecture), GERAM (Generalized Enterprise Reference Architecture and Methodology), GRAI/GIM (Graphs with Results and Activities Interrelated), and Object Flow Diagram (Greenwood, Pawlewski \& Bocewicz, 2013).

There are some methods, including mathematical programming, combinatorial optimization, Petri nets, and scenario analysis, 
that can be used for modeling the problems related with design of manufacturing systems (Chryssolouris, 2005), but a computer simulation, in particular Discrete Event Simulation (DES), is the most universal one (Banks et al., 2010).

The ability to carry on experiments that cannot be performed on the real manufacturing systems is the main advantage of DES. Also, a simulation model helps to gain expertise and experience that could lead to an improvement of the actual system (Sharma, 2015), for example detection of a bottleneck. There are many DES software tools dedicated to modeling of production systems, including ARENA, Enterprise Dynamics, FlexSim, Plant Simulation and others (Banks et al., 2010). The methodology of the modeling and the simulation process (Fig. 1) includes the analysis of the real problem, conceptual design and model synthesis, a simulation experiment and implementation of the obtained solution (Kampa, Gołda \& Paprocka, 2017).

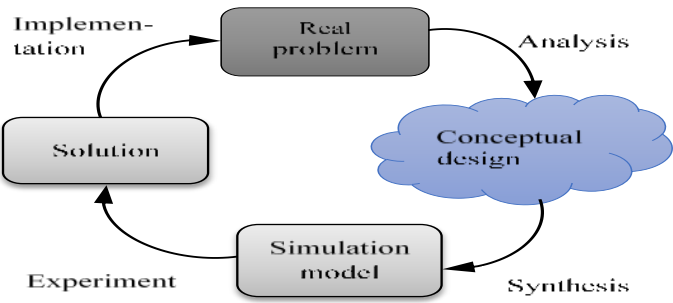

Fig. 1. The methodology of the modeling and simulation process The main problem at the stage of designing the manufacturing systems is establishing a real difference in the productivity between improved and reengineered manufacturing systems, for example, ones that are manually operated and other that are automated or robotized. Therefore, the aim of the current study is developing a method that allows us to clearly determine the productivity growth associated with an improvement of manufacturing systems at the early design stage, for example, the replacement of human operators with industrial robots. Actually, millions of industrial robots are used worldwide, especially for repetitive and high precision tasks (e.g., welding), monotonous or physical effort demanding activities. Industrial robots are built like a human arm and can perform handling or other various complex actions similarly to a human. Furthermore, they do not get tired and bored. As a result of robotization, many companies have obtained an increase in productivity of $30 \%$, reduction in production costs of $50 \%$, and an increase in utilization of means of production of more than $85 \%$ (Glaser, 2009). The application of industrial robots is associated with considerable costs; therefore, robotization will be profitable only under certain conditions, such as high level of production, repetitive work and precise tasks, and must ensure health and safety at work. These conditions exist in the automotive industry, where most robots are utilized (Hagele, Nilsson \& Pires, 2008)

Moreover, the next question is which parameters are important for the evaluation of this problem (Kampa, Gołda \& Paprocka, 2017). This concerns factors related to human-machine interaction. There is a large number of human factors that are difficult to model because of human individuality and varied behavior. On the other hand, factors related to machine parameters, machine maintenance, reliability and failures, should all be taken into account (Harriot \& Adams, 2013). The integration of the transportation system, storage system, and quality control system into FMS is also important

We will now consider an example of a conceptual design of a small manufacturing system, with $\mathrm{CNC}$ machine tools, which can be operated by humans or robots. The production process includes two machining operations of large and heavy parts, which are difficult in terms of handling, therefore robots are preferred. The production flow in the cell and internal logistic processes were modeled in the Enterprise Dynamics software, which enables simulation and visualization of discrete production processes. Two models are presented and compared using simulation experiments. The models were built taking availability, performance and quality parameters into account, what enables a direct calculation of OEE (Overall Equipment Effectiveness) indicator. OEE is one of the most important Key Performance Indicator (KPI) used in World Class Manufacturing methodology, especially in automotive industry. WCM is the development of the Kaizen and Lean Manufacturing ideas for continuous improvement of production processes with the use of standardized indicators. The use of OEE indicator enables comparison with similar manufacturing systems and is recommended in a mass production.

\section{Problem Description}

The manufacturing system includes a lot of specialized machines and human operators or robots that are required for materials handling. Usually, the role of an operator is loading and unloading products into and from the machine and transferring the product from one machine to a next production stage. Industrial robots can perform that work faster and more regularly compared to human operators.

Figure 2 presents a diagram of a production process used in the automotive sector. The manufacturing system consists of four CNC lathe machines and needs two operators or two robots. Each operator handles two machines that are working simultaneously. Two operations must be executed to turn two sides of various parts from a part family (sleeves and wheels). Because the parts are large and heavy, robots are a preferred option. What will happen if we replace the human operators with industrial robots? What productivity growth can we achieve?

Fig. 2. The schema of production process

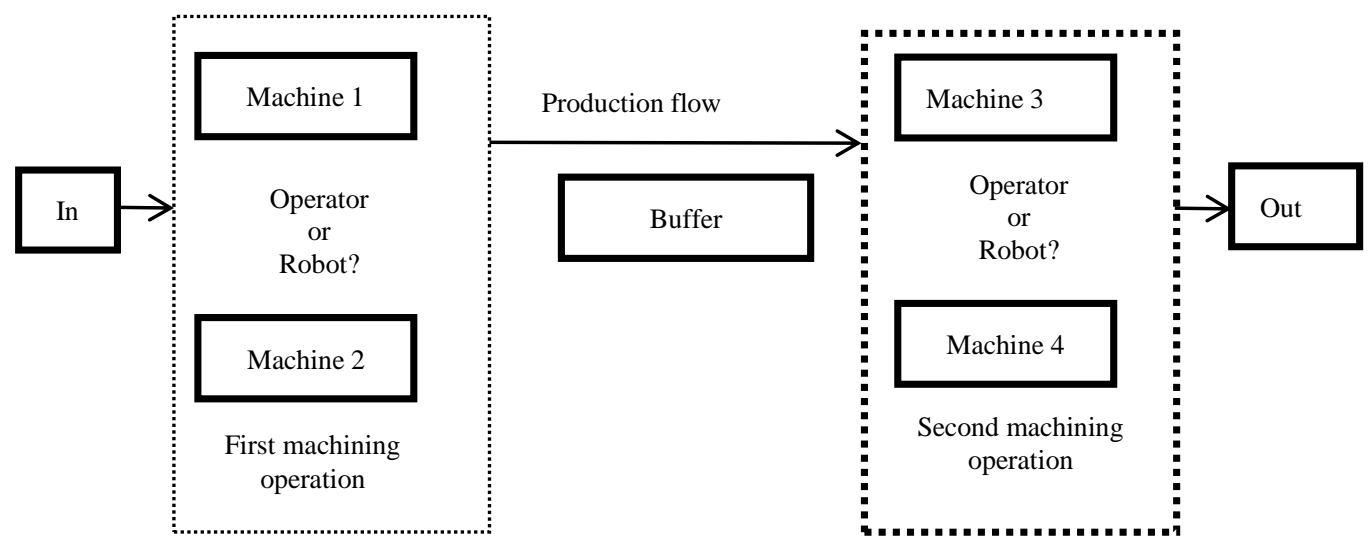

Several methods for robot motion planning have been described by (Genaidy \& Gupta, 1992; Nof, 1999). These methods are based on MTM (Method Time Measurement) or on the 
traditional time study concept and can be used to compare the relative abilities of robots and humans. A dedicated computer software for robot movement planning may also be used (Gołda \& Kampa, 2017). The result of each method is a set of time values that can be used to compare human and robot performance.

Although, robotized production lines are working very well, sometimes failures may occur. A failure of any elements of the line causes disturbances in the production flow or stops the production at all. Therefore, reliability of the components of the manufacturing system plays a key role in the productivity of a manufacturing system (Omron, Cassady \& Greenwood, 2002).

\section{Performance Indicators of Manufacturing System}

There are some Key Performance Indicators which can be used to evaluate of the manufacturing systems (Hansen, 2005):

- Production throughput,

- $\quad$ Manufacturing lead-time (MLT),

- The average waiting time of ready parts,

- Output queue length,

- Work in progress (WIP),

- OEE-Overall Equipment Effectiveness

Work efficiency and the use of the means of production can be expressed by using the OEE metric that depends on three factors: availability, performance and quality (Hansen, 2005).

$$
\mathrm{OEE}=(\text { Availability }) \times(\text { Performance }) \times(\text { Quality })
$$

Availability is the ratio of the time spent on the realization of a task to the scheduled time. Availability is reduced by planned and unplanned breaks at work and machine failures.

$$
\text { Availability }=\frac{\text { available time }- \text { failure time }}{\text { scheduled time }}
$$

Performance is the ratio between the time needed to complete a task under perfect conditions to the realization in real conditions or the ratio between the products obtained in real conditions and the number of products possible to obtain under perfect conditions. Usually, it is not possible to achieve ideal conditions and performance is reduced by below 100 percent because of some random disturbances e.g., human errors.

$$
\text { Performance }=\frac{\text { ideal cycle time }}{\text { real cycle time }}
$$

Quality can be calculated as the ratio of the number of good quality products compared to the total number of products.

$$
\text { Quality }=\frac{\text { good products }}{\text { overall products }}
$$

The number of good quality products is a random variable that can be described by a normal distribution with standard deviation sigma. The acceptable quality level can be specified according to ranges of the standard deviation. In traditional production systems, the level of 3 sigmas is considered to be sufficient. However, in the modern manufacturing systems, a level of 5-6 sigmas is possible to achieve; that means only three defects for one million possibilities (Barney \& McCarty, 2002). Next, we used the OEE (Overall Equipment Effectiveness) parameters to build a model of the analyzed manufacturing system and compare it with similar manufacturing systems.

\section{Machine Availability and Reliability}

The availability is heavily dependent to reliability and random failures of machines. The reliability of objects, such as machines, is defined as the probability of whether they will work correctly for a given time under defined conditions. The most popular method for estimating reliability parameters uses the theory of probability to forecast the value of any failure-free time and repair time parameters, which are based on historical observations.

In practice, in most cases, the parameter MTTF (Mean Time to Failure) is used to describe machine reliability, which is the expected value of the time until a failure of a machine occurs. For example, that time can be defined as exponentially distributed random variable with failure rate $\lambda$ (smith, 2005), which can be described as follows:

$$
\text { MTTF }=\int_{\frac{1}{\lambda}}^{\infty} \mathrm{t} f(\mathrm{t}) \mathrm{dt}=\int_{0}^{\infty} \mathrm{t} \lambda \mathrm{e}^{-\lambda \mathrm{t}} \mathrm{dt}=
$$

In the case of repairable objects, the parameters MTBF (Mean Time between Failures), and the MTTR (mean time to repair) are used:

\section{$\mathrm{MTBF}=\mathrm{MTTF}+\mathrm{MTTR}$}

Average inherent availability can be also calculated with formula 7 .

$$
\text { Availability }=\frac{M T B F}{M T B F+M T T R}
$$

In the industrial environment, the failures of machines are mostly random and are very difficult to predict; therefore, we are using a computer simulation for further research, similarly as presented by (Kampa, Gołda \& Paprocka, 2017). To create a model of the manufacturing line, we can use different failure parameters for machines, robots and human operators.

\section{Model Example}

In order to analyze the problem presented above, we have used Enterprise Dynamics software, which allows computer modeling and simulation of discrete production processes with the use of robots and human resource. Computer models of manufacturing systems operated by a human operator or a robot have been developed, consi(dering the planned interruptions of work and failure rates (Fig. 3 and 4).

The developed models include the input (Source), machines, human resources, robots, storage buffers (Queue), output element for good quality products (Good parts) and other for insufficient quality products (Bad parts) and control elements (Availability Control, Schedule, MTBF, MTTR).



Fig. 3. Model of human operated manufacturing system after 8 hours of simulation

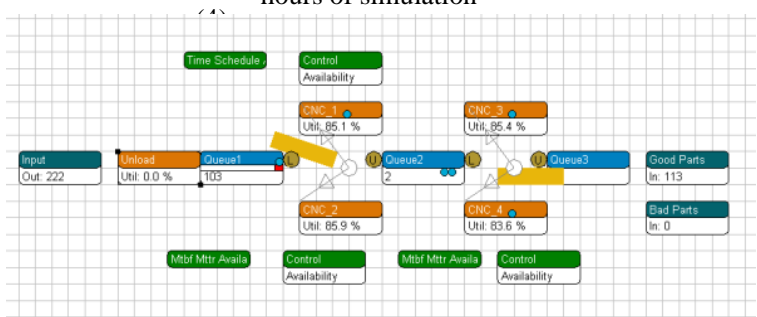

Fig. 4 Model of robotic manufacturing system after 8 hours of simulation

The process parameters were obtained from time study of similar manufacturing processes. The model includes a number of determined and stochastic work parameters: machine cycle time of different parts $\mathrm{Tm}=229 \div 610$ seconds (uniform distribution), time of the retooling 30 minutes (one time per shift).

In the case of failure, some disturbances in production flow occur, therefore we take into account long-time and short-time failure parameters of machines, operators and robots.

Reliability parameters for this machine type include MTBFm $=488$ hours and MTTRm $=4$ hours. For robots, it is 
MTBFr $=2000$ hours and $\mathrm{MTTRr}=4$ hours. There are also changing of used tools needed. It is required after $\mathrm{MTBFt}=10$ tool cycles and takes about MTTRt=1 minute.

The human reliability is related with sick leaves that take 10 days per year on average. It can be described with reliability parameters MTBFh=1000 hours and MTTRh=40 hours/per shift (Gołda, Kampa \& Paprocka, 2018). We assume that sometimes another employee can replace an ill and absent worker, but it is impossible to replace a broken machine or a robot, as these require repairs.

According to a time study, the human operator requires time $\mathrm{Tp}=27-49$ seconds for loading and unloading the machine. Assuming the human errors rate on the basis of (Woods, 1990), HEART (Human Error Assessment and Reduction Technique) for "routine and highly practiced rapid tasks involving relatively low level of skill", the nominal value of human error equals 0.01 . Therefore, human errors rate can be described by parameters: $\mathrm{MTBFh}=8$ hours and MTTRh $=5$ minutes

Human workers also need breaks for rest that take 15 minutes for an 8 hour shift, and that are implemented in the simulation schedule. The performance of the robotic cell is connected with faster robot movement by the loading of heavy parts into machine that take about $\operatorname{Tr}=23$ seconds. A robot can make this faster than an operator and is more reliable, what influences the system productivity. Quality levels of $99,9 \%$ for workers and $99,99 \%$ for robots were assumed.

The short time simulation shows only a small advantage of the robotic system, but with the longer simulation time the advantage of robotic system is more visible.

In the next step of model verification, also the stability of the production system and the impact of failure parameters on productivity and performance were analyzed similarly as presented by (Burduk, 2014).

Due to the random nature of failure processes, a single simulation does not give overall picture of the problem. Therefore, a number of simulation experiments with different simulation times and number of simulation runs were performed (from 8 to 6000 hours of work time).

The trend line of average production and the distribution histogram for the manually-operated system and for the robotoperated system are presented in Figures 5 and 6 respectively. The average value of production is in the "box" range with confidence level of $95 \%$. The "whiskers" show minimum and maximum production value from each experiment series.
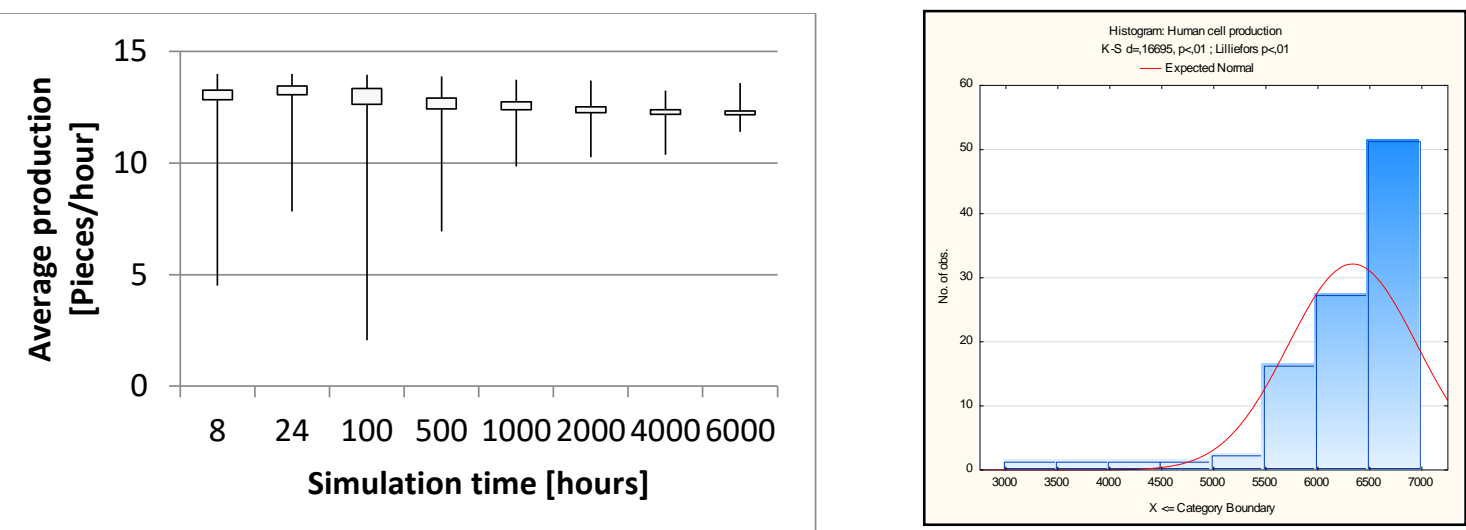

Fig. 5. The trend of average production value for manually-operated line and histogram of production variable for 500 hours of simulation
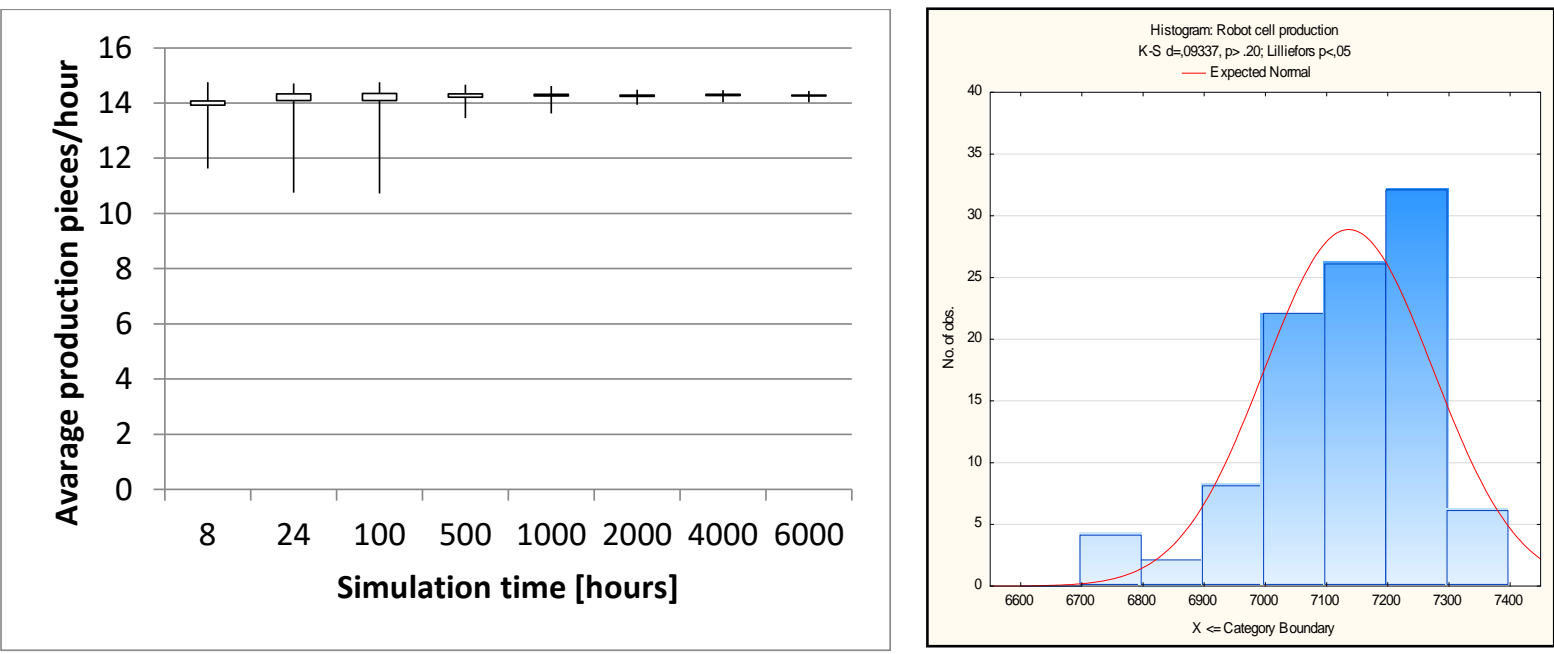

Fig. 6. The trend of production value for robotic cell and histogram of production variable for 500 hours of simulation

The trend of average production value for the model of robotic system is more stable than in the case of a manually operated line. There are some outliers (whiskers for the most extreme observations) represented by the minimum values of production (early failures).

During the first experiment, an asymmetrical distribution with the left skewness can be observed. For longer simulation time almost symmetrical normal distribution can be observed in both cases, but the model of the robotic system has a smaller range of values.
Experiments were conducted for one, two and three shifts and 250 working days per year in order to observe the influence of long-term failures. Detailed results of the experiments are presented in the next section.

\section{Simulation Results}

The production value $\mathrm{P}$ obtained from the simulation is a random variable which can take different values. Therefore, the average production values $\mathrm{P}_{\mathrm{avg}}$ from simulation experiments are summarized in Table 1. 
Table 1. Simulation results for manually operated and robotic cells (average production value $P_{\text {avg }}$ in [PCs.] for 100 samples, $\alpha=0,95$, MTBFm $=488 \mathrm{~h}, \mathrm{MTBFr}=2000 \mathrm{~h}, \mathrm{MTBFh}=1000 \mathrm{~h}$, $\mathrm{MTTRh}=40 \mathrm{~h}, \mathrm{MTTRr}=4 \mathrm{~h}$ and $\mathrm{MTBFm}=1000 \mathrm{~h} \mathrm{MTBFr}=2000 \mathrm{~h}$, $\mathrm{MTTR}=4 \mathrm{~h}$ )

\begin{tabular}{|c|c|c|c|c|}
\hline & $\begin{array}{l}\text { Human } \\
\text { Operato } \\
\text { rs }\end{array}$ & Robots & $\begin{array}{c}\text { Human } \\
\text { Operators }\end{array}$ & $\begin{array}{c}\text { Robot } \\
\mathrm{s}\end{array}$ \\
\hline & $\begin{array}{r}\text { MT } \\
\text { MT } \\
\text { MTBFr= }\end{array}$ & $\begin{array}{l}\mathrm{n}=488 \mathrm{~h} \\
=1000 \mathrm{~h} \\
\mathrm{~h} \text { MTTRr }=4 \mathrm{~h}\end{array}$ & $\begin{array}{r}\text { MTBFm= } \\
\text { MTBFh= } \\
\text { MTBFr= } \\
\text { MTTR }\end{array}$ & $\begin{array}{l}000 \mathrm{~h} \\
000 \mathrm{~h} \\
000 \mathrm{~h} \\
=4 \mathrm{~h}\end{array}$ \\
\hline & \multicolumn{4}{|c|}{ Simulation time 8 hours } \\
\hline $\begin{array}{l}\text { Production } \\
\text { Limit [PCs.] }\end{array}$ & 137,28 & 137,28 & 137,28 & $\begin{array}{c}137,2 \\
8\end{array}$ \\
\hline $\begin{array}{l}\text { Average } \\
\text { Production } P_{a v g} \\
{[\mathrm{PCs}]}\end{array}$ & 104,35 & 112,06 & 104,25 & $\begin{array}{c}111,7 \\
9\end{array}$ \\
\hline $\begin{array}{l}\text { Standard } \\
\text { deviation [PCs] }\end{array}$ & 8,63 & 3,09 & 13,02 & 5,13 \\
\hline $\begin{array}{l}\text { Relative } \\
\text { deviation }\end{array}$ & 0,0827 & 0,0276 & 0,1249 & $\begin{array}{c}0,045 \\
9\end{array}$ \\
\hline \multirow[t]{2}{*}{ OEE } & 0,7601 & $\mathbf{0 , 8 1 6 3}$ & $\mathbf{0 , 7 5 9 4}$ & $\begin{array}{c}0,814 \\
3\end{array}$ \\
\hline & \multicolumn{4}{|c|}{24 Hours } \\
\hline $\begin{array}{l}\text { Production } \\
\text { Limit } \\
\end{array}$ & 411,84 & 411,84 & 411,84 & $\begin{array}{c}411,8 \\
4 \\
\end{array}$ \\
\hline $\begin{array}{l}\text { Average } \\
\text { Production }\end{array}$ & 318,23 & 340,95 & 319,03 & $\begin{array}{c}344,0 \\
7\end{array}$ \\
\hline Std. dev. [Pcs] & 24,05 & 14,75 & 38,64 & 12,96 \\
\hline $\begin{array}{c}\text { Relative } \\
\text { deviation }\end{array}$ & 0,0756 & 0,0433 & 0,1211 & $\begin{array}{c}0,037 \\
7\end{array}$ \\
\hline \multirow[t]{2}{*}{ OEE } & $\mathbf{0 , 7 7 2 7}$ & $\mathbf{0 , 8 2 7 9}$ & 0,7746 & $\begin{array}{c}0,835 \\
4\end{array}$ \\
\hline & \multicolumn{4}{|c|}{2000 hours } \\
\hline $\begin{array}{l}\text { Production } \\
\text { Limit } \\
\end{array}$ & 34320 & 34320 & 34320 & 34320 \\
\hline $\begin{array}{l}\text { Average } \\
\text { Production }\end{array}$ & $\begin{array}{c}24777,9 \\
2 \\
\end{array}$ & 28529,91 & 24845,67 & $\begin{array}{c}28916 \\
, 21 \\
\end{array}$ \\
\hline Std. dev. [Pcs] & 1373,71 & 261,37 & 1452,97 & $\begin{array}{c}206,7 \\
8 \\
\end{array}$ \\
\hline $\begin{array}{l}\text { Relative } \\
\text { deviation }\end{array}$ & 0,0554 & 0,0092 & 0,0585 & $\begin{array}{c}0,007 \\
2 \\
\end{array}$ \\
\hline \multirow[t]{2}{*}{ OEE } & 0,7220 & 0,8313 & 0,7239 & $\begin{array}{c}\mathbf{0 , 8 4 2} \\
5\end{array}$ \\
\hline & \multicolumn{4}{|c|}{6000 Hours } \\
\hline $\begin{array}{l}\text { Production } \\
\text { Limit } \\
\end{array}$ & 102960 & 102960 & 102960 & $\begin{array}{c}10296 \\
0\end{array}$ \\
\hline $\begin{array}{l}\text { Average } \\
\text { Production } \\
\end{array}$ & $\begin{array}{c}73502,2 \\
9 \\
\end{array}$ & 85609,84 & 73711,91 & $\begin{array}{c}86783 \\
, 25 \\
\end{array}$ \\
\hline Std. Dev. [Pcs] & 2393,53 & 477,32 & 2760,68 & $\begin{array}{c}386,8 \\
6\end{array}$ \\
\hline $\begin{array}{l}\text { Relative } \\
\text { deviation }\end{array}$ & 0,0326 & 0,0056 & 0,0375 & $\begin{array}{c}0,004 \\
5 \\
\end{array}$ \\
\hline OEE & $\mathbf{0 , 7 1 3 9}$ & $\mathbf{0 , 8 3 1 5}$ & 0,7159 & $\begin{array}{c}\mathbf{0 , 8 4 2} \\
9\end{array}$ \\
\hline
\end{tabular}

Each experiment consists of a hundred simulation runs. The value ProductionLimit determines the maximum possible production volume in a given period of time at the ideal working conditions. It was calculated - for mean machine cycle time of 419,5 seconds and production rate of 17,16 pieces/hour.

Two scenarios with different reliability parameters were taken into consideration in order to observe its influence over productivity. The random nature of the failures causes a significant dispersion of obtained values and relatively large standard deviation, which is related with high production volume, but relative deviation is much smaller and decrease with time.

Since the model was build based on the OEE components, the production value from simulation can be directly used to calculate the OEE indicator with equation 8 .

$$
O E E=\frac{\text { Average production from simulation }}{\text { Production limit }}
$$

The experiment results show an increased production value of robotic system of about $17 \%$ compared to the human operated system. The OEE values are in the range from $71 \%$ to $77 \%$ for the human operated system (but it can be much lower in the case of long absence of a human operator). The OEE for robotic manufacturing system is in the range $81 \%$ to $84 \%$, which is very close to the $85 \%$ limit for WCM. The robotic system is also more stable with longer simulation time.

\section{Conclusions}

The computer simulation of the more sophisticated model of manufacturing system with machines, operators and robots with reliability parameters allows for better representation and understanding of a real production processes and may give major help in the early design stage of manufacturing system, because many possible variants can be analyzed.

As predicted, the experiments confirm the advantage of industrial robots application over manually operated machines. This is particularly visible in the case of work in three shifts for a long period of time. The production volume is greater by about $17 \%$ compared to human operated machines and average OEE has been improved by about $8 \%$. However, in this case the difference between a human operator and a robot is not as great as in other cases of robotization, because the robot is not fully utilized due to relatively long process time on the CNC machines. Experiments show that reliability of human operators, machines and robots plays a significant role, therefore, in each case of robotization, individual analysis is required.

The use of the standardized OEE indicator allows the comparison with other manufacturing systems. In the industrial reality most of manufacturing companies have OEE scores close to $50-60 \%$. There are also many companies with OEE scores lower than $40 \%$. Only a very small number of companies that have OEE scores higher than $85 \%$ can be called World Class Manufacturing. Generally, automation and robotization help in the improvement of production processes and the best results in mass production can be achieved.

Results obtained with the presented method can also be used in detailed designing of a manufacturing system and in economic analysis regarding labor costs and costs associated with investments in robotization.

\section{References}

i. Banks J., Carson J. S., Nelson B. L., Nicol D. (2010): Discrete-Event System Simulation. 5 ed. Upper Saddle River, NJ : Prentice Hall,

ii. Barney, M., McCarty, T., (2002) The new Six Sigma, Prentice Hall Professional, New York

iii. Burduk, A. (2014), "Stability Analysis of the Production System Using Simulation Models", Process Simulation and Optimization in Sustainable Logistics and Manufacturing, Springer, pp. 69-83.

iv. Chryssolouris, G. (2005). Manufacturing Systems-Theory and Practice; Springer: New York, NY, USA, 2005.

v. Doumeingts, G.; Vallespir, B.; Darracar, D.M. (1987). Design Methodology for Advanced Manufacturing Systems. Comput. Ind. Vol. 9, 271-296.

vi. Genaidy, A.M., Gupta, T. (1992). Robot and human performance evaluation. In "Human -Robot Interaction" Editor M. Rahimi, W. Karwowski, Taylor \& Francis, London, pp. 4-15

vii. Glaser ,A. (2009), Industrial robot. Industrial Press, New York,

viii. Gołda G., Kampa A. (2017). Manipulation and handling processes off-line programming and optimization with use of K-Roset. Modern technologies in industrial engineering 
V. ModTech 2017 International Conference, 14-17 June 2017, Sibiu, Romania. Bristol. 2017, art. 012150 s. 1-6,

ix. Gołda G., Kampa A., Paprocka I. (2018), Analysis of Human Operators and Industrial Robots Performance and Reliability. MPER, Volume 9 No. 1, pp. 24-33

x. Greenwood, A.; Pawlewski, P.; Bocewicz, G. (2013). A Conceptual Design Tool to Facilitate Simulation Model Development: Object Flow Diagram. In Proceedings of the 2013 Winter Simulation Conference. Washington, DC, USA, 8-11 December 2013; pp. 1292-1303.

xi. Hägele, M. Nilsson, K., Pires J. N. (2008), Industrial Robotics. Springer Handbook of Robotics. Springer, Berlin

xii. Hansen, Robert C. (2005). Overall Equipment Effectiveness. Industrial Press

xiii. Harriott, C. E., Adams, J. A. (2013). „Modeling Human Performance for Human-Robot Systems“, Reviews of Human Factors and Ergonomics, No 9, p. 1-94. http://rev.sagepub.com/content/9/1/94

xiv. Kamble P. G., Hebbal S. S. (2010), An Overview of Manufacturing Enterprise Modeling and Applications for CIM Environment. Contemporary Engineering Sciences, Vol. 3, No. 5, pp. $201-214$

xv. Kampa, A., Gołda, G., Paprocka, I. (2017). Discrete Event Simulation Method as a Tool for Improvement of Manufacturing Systems. Computers, 6, 10; doi:10.3390/computers6010010

xvi. Nof S. Y. (1999). Handbook of industrial robotics. John Wiley \& Sons, New York

xvii. Ormon S.W., Cassady C.R., Greenwood A.G. (2002) Reliability prediction models to support conceptual design. Reliability IEEE Transactions on, vol. 51, pp. 151-157,

xviii. Robinson, S. (2008). Conceptual modelling for simulation part I: Definition and requirements. J. Oper. Res. Soc. Vol. 59, pp. 278-290.

xix. Sharma, P. (2015). Discrete-Event Simulation, Int. J. Sci. Technol. Res. Vol. 4, pp. 136-140.

xx. Smith D.J. (2005). Reliability, Maintainability and Risk Practical methods for engineers, Elsevier, Oxford

xxi. Tolio, T. (2009). Design of Flexible Production SystemsMethodologies and Tools; Springer: Berlin, Germany, 2009.

xxii. Woods, D. D. (1990), Modeling and predicting human error, In J. Elkind, S. Card, J. Hochberg, and B. Huey (Eds.), Human performance models for computer-aided engineering Academic Press, pp. 248-274. 